\title{
A NOVEL COST-EFFICIENT DAYLIGHT-BASED LIGHTING SYSTEM FOR PUBLIC BUILDINGS: DESIGN AND IMPLEMENTATION
}

\author{
Murat Ayaz ${ }^{1,1}$, Ugur Yucel ${ }^{2}$, Koray Erhan ${ }^{3}$, and Engin Ozdemir ${ }^{4}$ \\ ${ }^{1}$ Kocaeli University, Department of Electric and Energy, Kocaeli, Turkey \\ ${ }^{2}$ Kocaeli University, Mechatronics, Kocaeli, Turkey \\ ${ }^{3}$ Istanbul Gedik University, Department of Electrical and Electronics Engineering Istanbul, Turkey \\ ${ }^{4}$ Kocaeli University, Energy Systems Engineering, Kocaeli, Turkey \\ Email:1murat.ayaz@kocaeli.edu.tr
}

\begin{abstract}
In this study, design and implementation of a new cost-efficient daylight-based lighting control system is proposed to provide energy saving in a public building with a conventional lighting system. Energy gain recovery and regional daylight utilization coefficients are obtained by conducting daylight measurements in all indoor spaces of the building where the proposed lighting system will be applied. Daylight value is continuously transferred to the control system through the pyranometer placed outside and the need for artificial lighting is calculated by using sectional daylight utilization coefficients. Thereby, maximum benefit from daylight is realized when unnecessary energy consumption for artificial lighting is reduced. Experimental measurement results show that the proposed daylight-based lighting control system provides an average energy efficiency of the building at the level of $60 \%$. Additionally, the required investment, such as operating cost and payback period for converting an existing conventional lighting system into the proposed system, are discussed in detail. Cost analysis shows that the payback period of the proposed system can be reduced by 5 years compared to the conventional system.
\end{abstract}

Keywords: energy-efficient buildings, daylight harvesting, lighting control system, energy efficiency, energy saving, cost-efficient systems, automation system design

\section{INTRODUCTION}

Getting a better quality of life requires environmental protection and the efficient use of natural resources. Achieving energy efficiency by applying new technologies in lighting is essential not only to reduce energy costs, but also to promote environmental and economic sustainability $[1,2]$. The energy consumed for the lighting of buildings constitutes a large part of the energy consumption. Electricity lighting covers $19 \%$ of the total electricity production in the world [3]. Commercial and office buildings are in the group of high energy-consuming buildings. While $14 \%$ of total electricity consumption in commercial buildings is spent on lighting, $11 \%$ of the energy consumed in houses is used for lighting and small appliances $[4,5]$. It is determined as $(100-1000) \mathrm{kWh} / \mathrm{m}^{2}$ per year depending on the location of office buildings, equipment used, working hours, ventilation use, and type of lighting. Approximately $40 \%$ of the total electricity consumed in office buildings is used for lighting [6-8].

New materials and systems are necessary to reduce the need for lighting and preserve the lighting comfort of users $[9,10]$. By using energy-saving lamps, $40 \%$ of energy savings are achieved by using a combination of occupancy lighting with presence and absence sensors and utilizing daylight [11-13]. The rapid development of detection and microcontroller technologies has enabled the de- 
sign and use of high energy efficient lighting systems built on new smart lighting platforms. Control of artificial lighting standardizes user comfort while reducing energy consumption [14-19]. Open or closed-loop controlled lighting can be used as a control tool [20]. In the study conducted by Chew et al., a closed-loop controlled lighting system has been established and autonomously shaped based on the data received from the light sensors installed together with the LED lighting system. Luminaire luminous flux is provided by amplitude modulation depending on the sensor feedback information. The system saves $55 \%$ of energy in continuous use under test conditions. In addition, the system is commercially $31.52 \%$ cheaper compared to a system having manual dimming and a PIR detector [14]. In another study, Sahana et al. designed a daylight-based system using LDR (light-dependent resistance) and PIR (passive infrared sensor) sensors. In the developed system, when there is no user in any room or if the daylight level is sufficient, artificial lighting is turned off and electricity consumption is reduced. Artificial lighting control was carried out by determining different reference voltage levels for daylight range depending on the seasonal changes. The low-cost controller with both sensors integrated was implemented to a small room for lighting control and high efficiency was achieved [16]. Like the studies mentioned above, Dun carried out a study aimed at optimizing smart lighting in the university classroom and reducing energy consumption. In the study, the fuzzy model reference adaptive system (FMRAS) control algorithm was used. It has found that FMRAS has better control performance, higher steady state accuracy, lower overload rate, and higher response rate than typical fuzzy controllers currently used [18]. In another study on classroom lighting control, a lighting control system based on machine vision technology has been proposed to increase energy efficiency. It was found that a different number of signals could comprehensively control the level of illuminance created by classroom luminaires, and save energy used in classroom lighting [19].

The use of daylighting saves energy used for lighting, achieve high luminous flux, low heat dissipation compared to high illuminance level, protects the environment, better quality visual lighting compared to artificial lights, reduces stress and increases efficiency in workspaces since its human-friendly feature $[15,21-24]$. When the literature is examined, it is seen that (20-60) \% of the energy used for lighting is saved by using daylight harvesting systems (DHS) [25]. The study performed by Pandharipande et al. aimed to provide lighting comfort and energy saving for users in an office by optimizing artificial light sources with changing daylighting, and it is proposed to use sensors in the user platform as an alternative to the sensors used in the armature platform. If the sensors are placed at the user level, the illuminance level has been measured $10 \%$ lower and consequently more energy is consumed. If the occupancy rate of the office space is above $25 \%$, it is seen that the control system should be disabled due to the decrease in the illuminance level of the working spaces [26]. In the study performed by Tang et al., daylight harvesting system is applied by using a smartphone in smart home systems. The illuminance level of a room with 3 luminaires is measured by using the light sensor feature of the smartphones, the luminaire luminous flux are controlled by amplitude modulation in the $A r$ duino processor, and Raspberry $P i$ is used to connect the system with the mobile application editor.

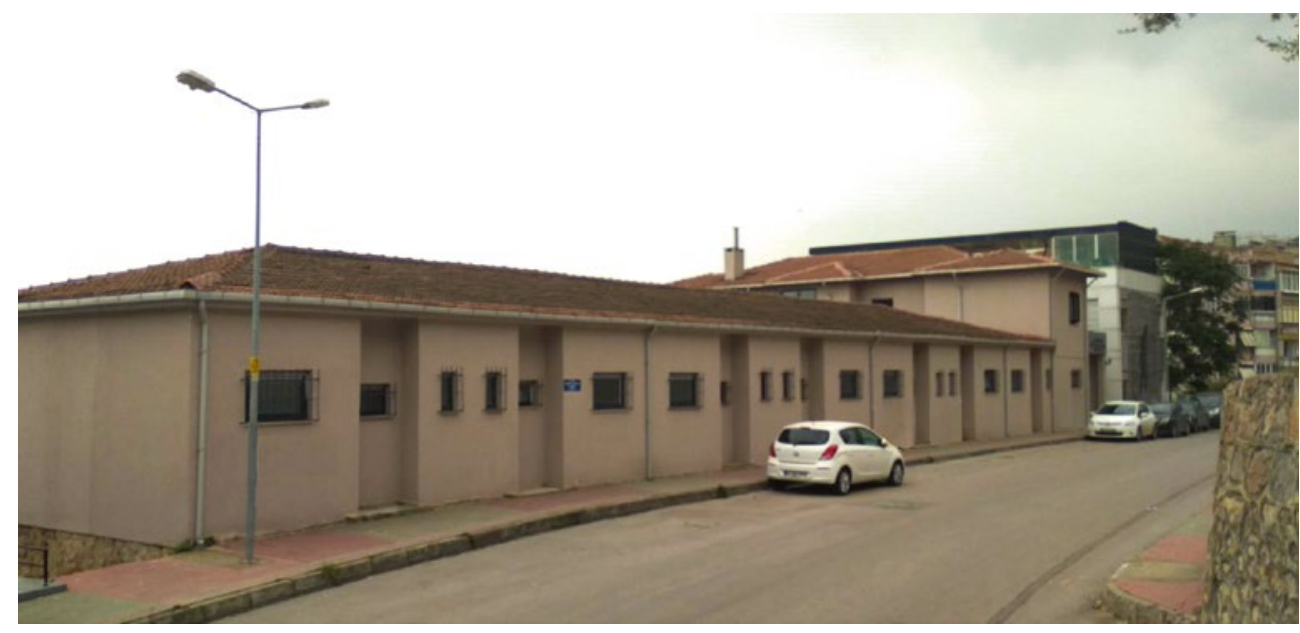

Fig. 1. Study object 

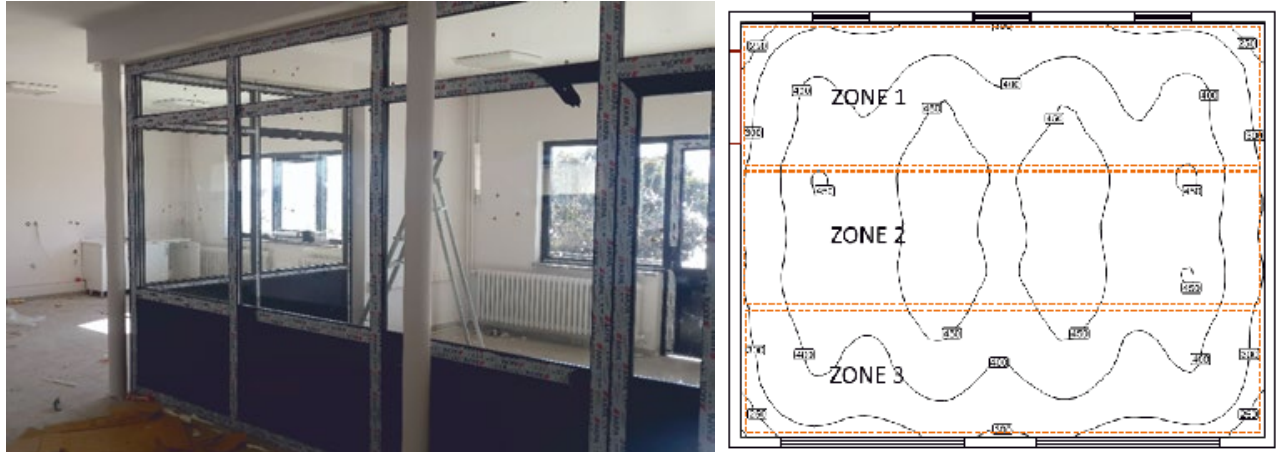

Fig. 2. Material laboratory and isolines on the working surface
$54.7 \%$ of energy savings are achieved on sunny days [27]. In another study of daylight-based lighting system, Meugheuvel et al. used a light sensor, which provides information about the local illuminance level under each luminaire in an open space office, and occupancy sensor. A control device is used to adjust the dimming level of the luminaire. According to the readings of light sensors, it is aimed to achieve the standard illumination levels for working zones and unused zones by using PI control. Two scenarios are applied. In the first scenario, each controller is operated independently, and it is found that the desired reference value could not be achieved in each case. The lighting reference value is captured through the PI controllers on the network, while a high saving in power consumption is achieved [28].

In this study discusses the energy savings, which can be achieved with a daylight-based lighting system for a building with a conventional lighting system, and recovery period of installation cost. Sections and utilization coefficients are determined by performing daylighting measurements in all indoor areas of the building within the specified time. The proposed lighting system components and control algorithm have been formed based on the number of sections The results obtained in the course of experimental measurements and analysis of the results are described in detail in the conclusion.

\section{EXPERIMENTAL METHOD}

\subsection{Application Building}

The building where the daylight-based lighting control system will be installed consists of 10 independent laboratories and offices. It has a total indoor area of $641 \mathrm{~m}^{2}$. In the building shown in Fig. 1, the application laboratories are located on the ground floor, and the personnel departments are located on the first floor. The lighting installation for offices and laboratories consists of 75 luminaires $(4 \times 18 \mathrm{~W})$ with fluorescent lamps using with on/off control. The instantaneous power consumption is $5.4 \mathrm{k} \cdot \mathrm{W}$, and the energy consumption for lighting for 8 hours shift is $43.2 \mathrm{~kW} \cdot \mathrm{h}$.

\subsection{Daylight Measurements}

Measurements are performed over three months to find the utilization rate of daylight during the working hours in all the internal spaces in the building. Zones of lighting are specified by using individual daylighting measurement values for each office and laboratory. 26 zones of lighting have appeared for 10 detached internal spaces inside the building. The measurements for material laboratory of the building with different facades are detailed below.

In the material laboratory shown in Fig. 2, lighting installation consists of 16 pieces of luminaires $(4 \times 18 \mathrm{~W})$ with fluorescent lamps. In addition, the laboratory has a window area of $7.56 \mathrm{~m}^{2}$, due to which daylighting can make a significant contribution to illuminance of workspaces. The area is divided into 3 zones, considering luminaire layout and the distribution of daylighting. The first zone is the farthest from the windows and there are 4 luminaires with a total power of $288 \mathrm{~W}$. The third zone is the closest to the window, and total artificial lighting power is $288 \mathrm{~W}$. In the zone defined as zone 2 , there are 8 luminaires with a total power of $576 \mathrm{~W}$.

The contribution of daylighting on 3 zones in the material laboratory between (09:00-17:00) working hours is shown in Fig. 3. The desired level of illuminance in the laboratory should be $500 \mathrm{~lx}$ of the reference value. In this respect, the daylight utilization rate and the need for artificial lighting are specified by comparing the change of daylighting in zones without artificial lighting and reference value. When the graphs given in Fig. 3 are examined, daylight- 


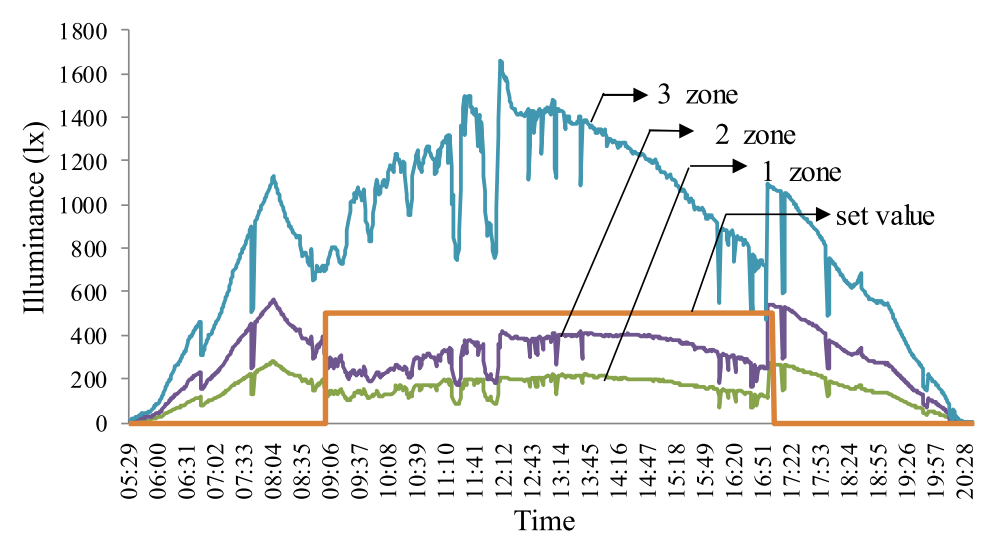

Fig. 3. The contribution of daylight in the material laboratory during working hours

ing contributes to the illuminance of the zones by $36 \%$ at the first zone, $64 \%$ at the second zone, and $100 \%$ at the third zone. The energy requirement for lighting the first zone during working hours is $2304 \mathrm{~W} \cdot \mathrm{h}$. While $830 \mathrm{~W} \cdot \mathrm{h}$ of that energy is supplied by daylighting, $1474 \mathrm{~W} \cdot \mathrm{h}$ of energy must be supplied through the network. In the second zone, $3000 \mathrm{~W} \cdot \mathrm{h}$ of the total energy demand of $4608 \mathrm{~W} \cdot \mathrm{h}$ is met by daylighting and $1608 \mathrm{~W} \cdot \mathrm{h}$ of energy is withdrawn from the network. In the third zone, artificial lightening is not required due to the high contribution of daylighting in the specified time.

\section{DAYLIGHT-BASED LIGHTING SYSTEM}

\subsection{Daylight Automation System}

In daylight-based lightening systems, the correct measurement or calculating the effect of daylighting on the indoors is of great importance for lighting control. In this context, the most used method is closed-loop controlled structures. In such systems, sensors are placed in each designated indoor space to transfer the level of illuminance to the control system instantly. Although the use of multiple sensors allows an easier and correct control, it poses a major disadvantage in terms of installation cost. Furthermore, the need to verify each sensor by checking their calibration regularly leads to increased operating costs. In this context, the system recovery time can be shortened by reducing installation and operating costs through the installation of an open-loop controlled lighting system. Moreover, the conversion of conventional lighting systems into a daylight-controlled automation structure can be achieved with fewer components via openloop control.

In this study, the proposed daylight-based lighting system is constituted with an open-loop control structure, and the control block diagram is given in Fig. 4. In the proposed system, daylighting is transferred to the control system instantly by using a pyrometer placed in the outdoor environment. The transfer coefficient of daylighting in each designated indoor zone is determined with experimental measurements. The need for artificial lighting is calculated for each zone by evaluating instant daylighting.

The controller calculates the amount of artificial lighting for areas where there is insufficient daylighting regionally. The required voltage rating in the luminaires is specified to meet the need for artificial lighting. The proposed lighting control system is installed in the Industry 4.0 laboratory. 6 existing luminaires $(4 \times 18 \mathrm{~W})$ with $\mathrm{T} 8$ type

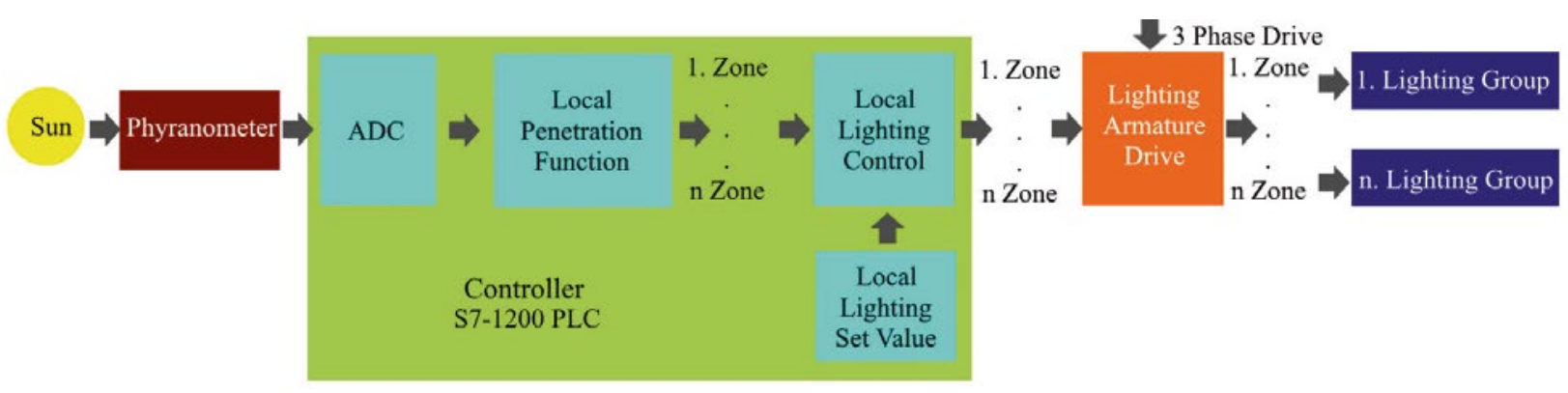

Fig. 4. Lighting automation system control block diagram 

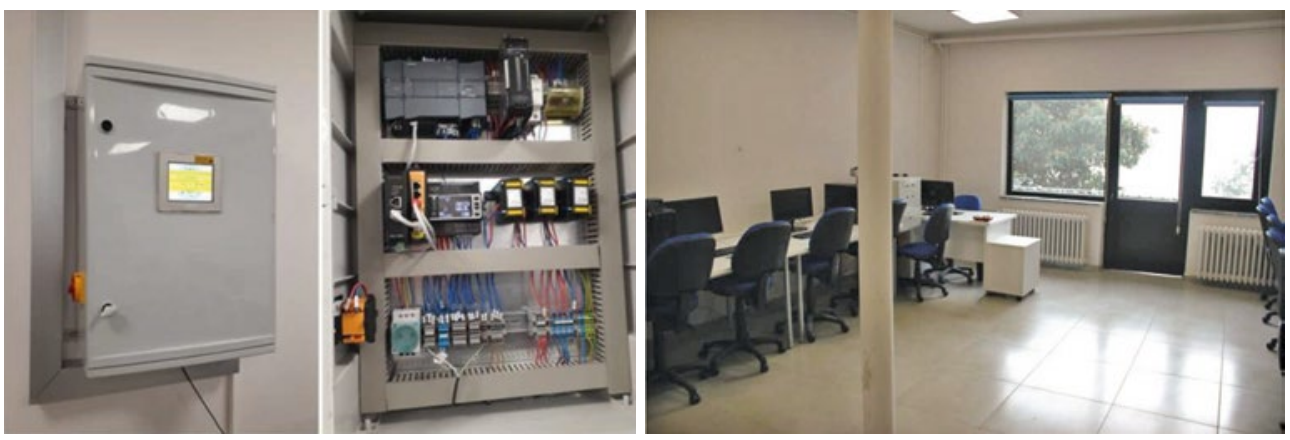

Fig. 5. Daylighting automation panel and Industry 4.0 laboratory fluorescent lamps are removed and replaced with 6 LED luminaires $35 \mathrm{~W}$ by Ledova. The luminaires are grouped in pairs concerning their distance from windows that are a daylighting source, location of existing luminaires and workspaces, and a total of 3 lines are formed. The value of the analogue voltage (0-5) $\mathrm{V}$ obtained from the pyranometer is transferred to the system via the S7-1200 PLC analogue input unit on the control panel shown in Fig. 5. One pyranometer is used for outdoor daylighting radiance measurement. In the PLC, the luminaires are controlled in the range of $(0-10) \mathrm{V}$ in line with the created algorithm by calculating the amount of required artificial lighting based on the amount of daylighting. Total current, voltage and power values of the network and each line are measured with the analyser. Measured values are transmitted from the analyser to the PLC via Ethernet. All measured values can be read from the panel. Data can be saved to the memory card on the pan-
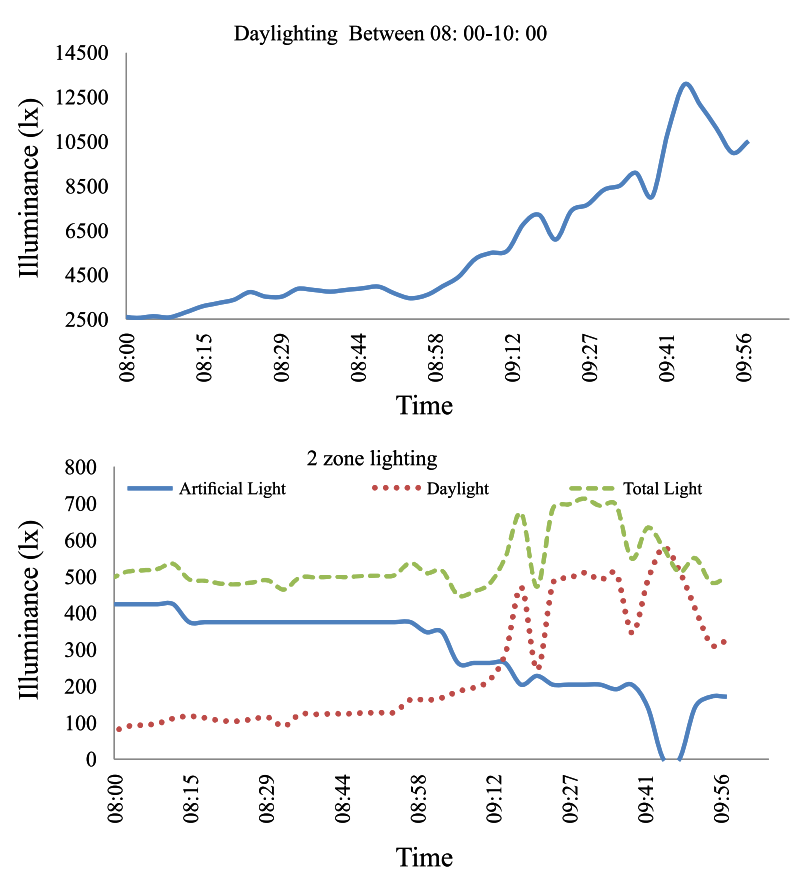

el. Also, the system can be accessed and intervened via the internet.

The measured values should be made as linear as possible to produce daylight saving coefficient in each zone specified in Industry 4.0 laboratory. Zone coefficients can be calculated based on time, as well as calculated by considering the effect value of the amount of daylighting. In this study, the coefficients are determined by considering the effect of daylighting on the zones. Measured values are categorized according to the first zone, where daylighting has the least effect, and the voltage ratings of luminaires in line with the needs of the zones are determined. The number of categories has kept high due to the eye-straining effect of sudden changes in the level of illuminance. A smooth transition is provided to increase or decrease the level of illuminance received from artificial light sources. Table 1 shows the determined groups of illuminance levels, the amount of daylighting impacting zones,
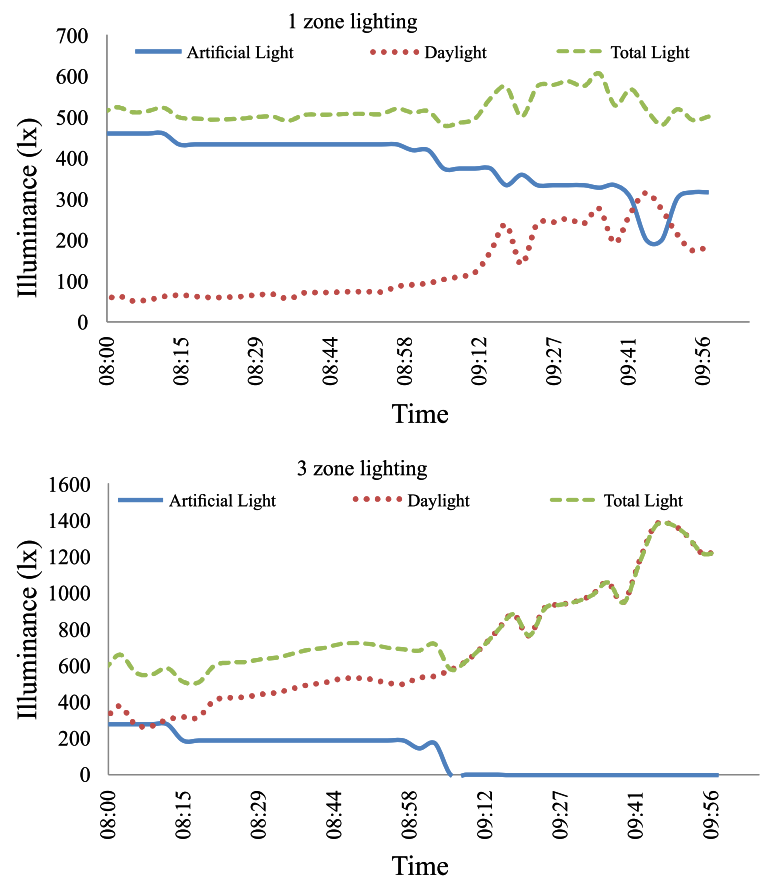

Fig. 6. Illuminance between (08:00-10:00) 

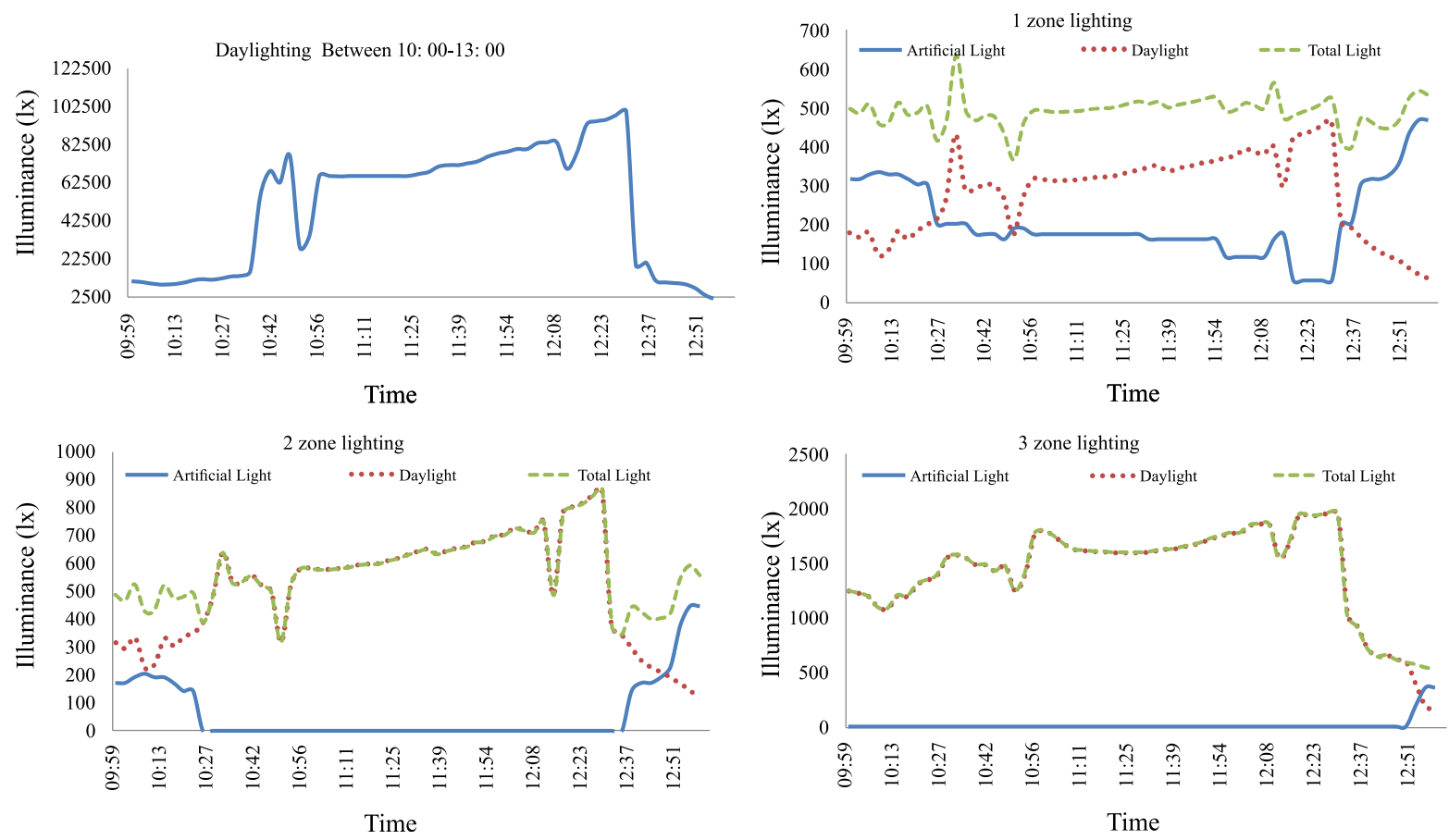

Fig. 7. Illuminance between (10:00-13:00)

the amount of artificial lighting required for these zones, and the analogue voltage rating that the controller should apply to the luminaires to obtain the artificial lighting.

\subsection{Experimental Performance of Daylight Automation System}

The proposed lighting control system is operated in line with the coefficients specified in the previous section. The measurement is performed by placing luxmeters in each zone for measuring the system can achieve the desired illuminance level in designated areas. As a result of the measurements, daylighting illuminance values are divided according to time, and the measured levels of illuminance readings for each zone during the working hours are shown in Fig. 6 and Fig. 7. For modelling have examined and graphed the hours between (08:00 10:00) and (10:00-13:00). Segmentation is made depending on the change for daylighting. Between (08:00-10:00), the amount of daylighting increases slightly, but illuminance produced by daylighting increaseы significantly between (10:00-13:00).

The level of illuminance at zone 1 is taken between (8:00-10:00). The low amount of daylighting increases the need for artificial light sources. A delay is added to the system due to the negative effects of sudden illuminance changes on eye health, thus the total illuminance level increases up to $590 \mathrm{~lx}$.
Daylighting has a higher impact on zone 2, and the need for artificial lighting has decreased. The third zone is the area that makes the most use of daylighting, since it is located next to the window. The need for artificial lighting is minimal. The required artificial lighting decreases with increasing daylighting. It is seen that the power consumption decreases according to time by zones. By 09:05, the power consumption in zone 3 was $0 \mathrm{~W}$.

If LED luminaires are installed instead of existing 6 luminaires $(4 \times 18 \mathrm{~W})$ with fluorescent lamps in Industry 4.0 laboratory, the installed power capacity decreases from $432 \mathrm{~W}$ to $210 \mathrm{~W}$. Table 2 shows that the energy consumption during the 8 -hours working hour decreased from $3456 \mathrm{~W} \cdot \mathrm{h}$ to $1680 \mathrm{~W} \cdot \mathrm{h}$. Using LED luminaires instead of luminaires with fluorescent lamps saved $48 \%$ of energy.

In the proposed lighting control system, LED luminaire is used instead of luminaires with fluorescent lamps, and the illuminance level of the outdoor area is measured by a sensor and LED luminaires are turn on as necessary. It is experimentally shown that the desired illuminance level for each zone is realized due to the maximum use of daylighting. The electrical energy consumed by the lighting system during the day is measured and given in Table 2 . The percentage of energy efficiency may vary depending on parameters such as weather conditions, seasons, glass pollution. The Table shows that the target lighting system provides (33-83) \% ener- 
Table 1. DIM Voltages to Be Applied to Obtain Required Artificial Lighting in Industry 4.0 Laboratory

\begin{tabular}{|c|c|c|c|c|c|c|}
\hline \multirow{2}{*}{ Daylighting range (kIx) } & \multicolumn{3}{|c|}{$\begin{array}{c}\text { The amount of daylighting affecting } \\
\text { the zones (lx) }\end{array}$} & \multicolumn{3}{c|}{$\begin{array}{c}\text { The amount of artificial lighting needed } \\
\text { in the zones (lx) }\end{array}$} \\
\hline & $\mathbf{1}$ zone & $\mathbf{2}$ zone & 3 zone & 1 zone & 2 zone & 3 zone \\
\hline $0-0.2$ & 0 & 0 & 0 & 500 & 500 & 500 \\
\hline $0.2-0.9$ & 8 & 15 & 50 & 492 & 485 & 450 \\
\hline $0.9-1.9$ & 31 & 55 & 141 & 469 & 445 & 359 \\
\hline $1.9-2.9$ & 39 & 75 & 220 & 461 & 425 & 280 \\
\hline $2.9-3.9$ & 66 & 124 & 310 & 434 & 376 & 190 \\
\hline $3.9-4.8$ & 80 & 151 & 353 & 420 & 349 & 147 \\
\hline $4.8-5.7$ & 125 & 236 & 499 & 375 & 264 & 1 \\
\hline $5.7-6.9$ & 140 & 271 & 602 & 360 & 229 & 0 \\
\hline $6.9-8.8$ & 165 & 295 & 850 & 335 & 205 & 0 \\
\hline $8.8-9.7$ & 171 & 308 & 974 & 329 & 192 & 0 \\
\hline $9.7-10.9$ & 183 & 328 & 1136 & 317 & 172 & 0 \\
\hline $10.9-11.9$ & 197 & 357 & 1220 & 303 & 143 & 0 \\
\hline $11.9-19.0$ & 298 & 519 & 1410 & 202 & 0 & 0 \\
\hline $19.0-55.4$ & 310 & 535 & 1500 & 190 & 0 & 0 \\
\hline $55.4-69.7$ & 325 & 597 & 1623 & 175 & 0 & 0 \\
\hline $69.7-78.7$ & 338 & 622 & 1652 & 162 & 0 & 0 \\
\hline $78.7-83.7$ & 383 & 710 & 1826 & 117 & 0 & 0 \\
\hline $83.7-100.0$ & 444 & 820 & 1948 & 56 & 0 & 0 \\
\hline $100.0-120.0$ & 490 & 944 & 2183 & 10 & 0 & 0 \\
\hline & & & & & & \\
\hline
\end{tabular}

gy efficiency in the zones and $59 \%$ energy efficiency on average.

Depending on the results of the study conducted in the Industry 4.0 laboratory, the installed power of the workspaces consisting of 10 laboratories and offices in the building, the amount of energy spent on an 8 hours shift, and the effect of daylighting on the regions are determined. Table 3 shows operating and percentage values of the installed power in the workspaces with daylight, the amount of consumption from 09:00 hours to 17:00 hours, the contribution of daylighting. 79 pieces of the existing luminaires $(4 \times 18 \mathrm{~W})$ with $\mathrm{T} 8$ fluorescent lamps are used, and the installed power is $5688 \mathrm{~W}$. If the luminaires are continuously active and on/off controlled for 8 hours shift, then the consumed energy is $45504 \mathrm{~W} \cdot \mathrm{h}$.

The power and energy consumption values are determined in case of replacing 79 existing luminaires in all work environments with built-in panel LED luminaires $((600 \times 600) \mathrm{mm}$ Ledova PL1400125 Olea, $35 \mathrm{~W})$, used in Industry 4.0 laboratory and controlling the luminous flux depending on the daylighting received from a single sensor. If the LED luminaires are operated in on/off mode, the consumption in 8 hours will be $22120 \mathrm{~W} \cdot \mathrm{h}$, and the energy consumption through daylighting control is decreased to $13228 \mathrm{~W} \cdot \mathrm{h}$.

\section{COST ANALYSIS}

The system is designed for 10 independent zones used in central laboratories and student affairs building and can be used to improve energy efficiency by lighting control. In the study, there was no control system work for corridors, storage areas, archives, and toilets. Cost analysis is performed for the areas where the daylighting control system is installed. There is a total of 79 luminaires $(4 \times 18 \mathrm{~W})$ with fluorescent lamps in the controlled areas.

In conventional lighting systems, luminaires are controlled by using on/off switches. In the case of illuminance of laboratories using different lighting methods, the required expenditures are shown in Table 4. The installation cost for lighting the spaces requiring control in our building by conventional methods is 3884 \$. LED luminaires are used in conventional daylight-based lighting systems, and 
Table 2. Comparison of Daylight-Controlled Lighting System Designed with on/off Control

\begin{tabular}{|l|l|c|c|c|c|}
\hline & \multicolumn{1}{|c|}{} & $\begin{array}{c}\mathbf{1} \text { zone } \\
\text { Energy } \\
\text { consumption } \\
\mathbf{( W \cdot h )}\end{array}$ & $\begin{array}{c}\mathbf{2} \text { zone } \\
\text { Energy } \\
\text { consumption } \\
\mathbf{( W \cdot h )}\end{array}$ & $\begin{array}{c}\text { 3 zone } \\
\text { Energy } \\
\text { consumption } \\
\text { (W·h) }\end{array}$ & $\begin{array}{c}\text { Total } \\
\text { Energy } \\
\text { consumption } \\
\text { (W·h) }\end{array}$ \\
\hline 1 & $\begin{array}{l}\text { On/off controlled consumption } \\
\text { (fluorescent) }\end{array}$ & 1152 & 1152 & 3456 \\
\hline 2 & On/off controlled consumption (LED) & 560 & 560 & 560 & 1680 \\
\hline 3 & $\begin{array}{l}\text { Daylighting control for LED } \\
\text { luminaires }\end{array}$ & 375 & $48 \%$ & 658 \\
\hline $\begin{array}{l}\text { Comparison of on/off controlled ex- } \\
\text { isting lighting installation and on/off } \\
\text { controlled LED lighting installation }\end{array}$ & $48 \%$ & $48 \%$ & $48 \%$ \\
\hline $\begin{array}{l}\text { Comparison of on/off controlled LED } \\
\text { lighting installation and daylighting } \\
\text { control LED lighting installation }\end{array}$ & $33 \%$ & $61 \%$ & $83 \%$ & $59 \%$ \\
\hline
\end{tabular}

Table 3. The Effect of Daylighting on Workspaces

\begin{tabular}{|c|c|c|c|c|c|c|c|}
\hline 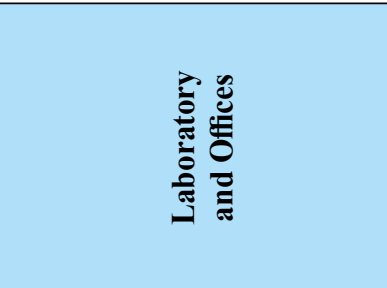 & 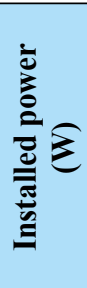 & 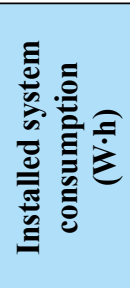 & 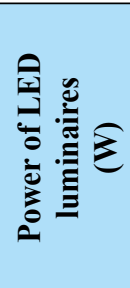 & 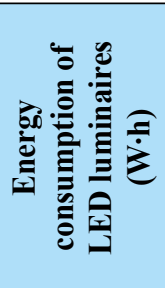 & 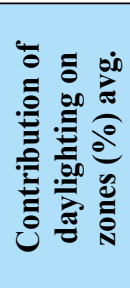 & 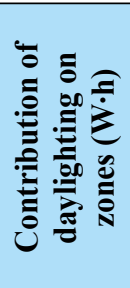 & 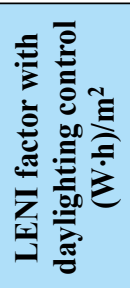 \\
\hline Materials laboratory & 1000 & 9000 & 560 & 4000 & $70 \%$ & 2500 & 26.1 \\
\hline Casting laboratory & 864 & 6912 & 420 & 3360 & $63 \%$ & 2128 & 28.4 \\
\hline Electric Engine laboratory & 864 & 6912 & 420 & 3360 & $63 \%$ & 2128 & 31.4 \\
\hline Industry 4.0 laboratory & 432 & 3456 & 210 & 1680 & $60 \%$ & 1008 & 3.1 \\
\hline Robotics laboratory & 432 & 3456 & 210 & 1680 & $64 \%$ & 1087 & 23.4 \\
\hline Academic staff room & 432 & 3456 & 210 & 1680 & $56 \%$ & 936 & 26.7 \\
\hline Student affairs main office & 168 & 4032 & 245 & 1960 & $61 \%$ & 1196 & 26.5 \\
\hline Documentation office & 432 & 3456 & 210 & 1680 & $40 \%$ & 663 & 17.6 \\
\hline Management office & 288 & 2304 & 140 & 1120 & $80 \%$ & 896 & 44.8 \\
\hline Support office & 288 & 2304 & 140 & 1120 & $22.5 \%$ & 252 & 12.6 \\
\hline Total & 5688 & 45504 & 2765 & 22120 & $59 \%$ & 13228 & \\
\hline
\end{tabular}

Note to Table 3: The lighting energy numerical indicator (LENI) method provides an alternative way of calculating the lighting energy performance of a building. Whereas each luminaire is usually assessed for its energy efficiency (for example a luminaire with no controls should have a minimum efficiency of 60 luminaire lumens per circuit watt), the LENI method calculates the actual energy used in $\mathrm{kW} \cdot \mathrm{h}$ per square meter per year. This figure is then assessed against a maximum benchmark value depending on the illuminance $(\mathrm{lx})$ required within a room.

there is a sensor that measures the illuminance level in every workspace or under each luminaire. The use of a controller is mandatory for processing sensor information and driving luminaires. The controller also provides data monitoring and remote access to the system. Using an energy analyser to measure site data enables the measurement of energy savings. Luminaires must be suitable for DIM operation. LED luminaires are appropriate for control structure. The system must have a sensor that can measure the illuminance level of 10 closed areas, and a control structure that can drive 26 zone luminaires. In the case of lighting zones with conventional daylight-based lighting system, the cost 
Table 4. Cost Analysis Table

\begin{tabular}{|c|l|c|c|c|c|}
\hline \multicolumn{2}{|c|}{$\begin{array}{c}\text { Components } \\
\text { On/off lighting } \\
\text { system (fluorescent) }\end{array}$} & $\begin{array}{c}\text { On/off lighting } \\
\text { system (LED) }\end{array}$ & $\begin{array}{c}\text { Conventional } \\
\text { daylight-based } \\
\text { lighting system }\end{array}$ & $\begin{array}{c}\text { Proposed daylight- } \\
\text { based lighting } \\
\text { system }\end{array}$ \\
\hline 1 & Luminaries & $2756 \$$ & $3635 \$$ & $9042 \$$ & $9042 \$$ \\
\hline 2 & Sensors and detectors & - & - & $4500 \$$ & $450 \$$ \\
\hline 3 & Controller and components & - & - & $5350 \$$ & $4919 \$$ \\
\hline 4 & Cabling infrastructure & $615 \$$ & $615 \$$ & $1285 \$$ & $1117 \$$ \\
\hline 5 & Installation work & $513 \$$ & $513 \$$ & $1010 \$$ & $945 \$$ \\
\hline \multicolumn{2}{|c|}{ Total } & & $\mathbf{4 7 6 3 \$}$ & $\mathbf{2 1 1 8 7} \$$ & $\mathbf{1 6 4 7 3} \$$ \\
\hline
\end{tabular}

of installation is 21187 \$. Unlike conventional daylight-based lighting system, the proposed system uses a single sensor. Using a single sensor saves the inputs of the controller. The proposed single-sensor daylight-based control system has an installation cost of 16473 \$.

According to the 2019 tariff applied in schools in Turkey, the cost of $1 \mathrm{~kW} \cdot \mathrm{h}$ of electricity reflected to the consumer is $14.89 \mathbb{C}$ [29]. If the LED luminaire is used instead of the luminaire with T8 fluorescent lamps, an added $879 \$$ will be added to the installation cost. In case of using LED luminaire instead of the luminaire with fluorescent lamps, the excess cost can be compensated within 1 year. If a conventional (sensor in each working area) daylight-based lighting system is installed instead of a luminaire with T8 fluorescent lamps, an added investment of 17303 \$ is required.

\section{CONCLUSION}

A single sensor and open-loop control system is created as an alternative to conventional daylighting control systems. Daylighting illuminance levels are measured depending on daylight in indoors spaces where control system will be applied. Daylight factors of these spaces are determined accordingly. The experimental system has been installed in the Industry 4.0 laboratory. Existing luminaires are replaced with DIM controlled LED luminaires, and their operating performance is examined depending on/off operating mode and daylighting. The performance of current conventional luminaires, LED luminaires and daylight-controlled LED luminaires are compared. When the LED luminaires are operated in on/ off mode, it is found that they are $48 \%$ more efficient than conventional lighting systems. Daylighting value is measured with a single sensor placed outdoors, and the luminaires are dimmed depending on daylighting. Empirically, $59 \%$ energy savings are achieved. The cost analysis is performed and compared with the current conventional lighting if the system is installed throughout the building. It is seen that the start-up costs of current conventional lighting systems are lower than the daylighting control systems; however, a single-sensor openloop controlled daylighting control system achieved high energy efficiency. Despite its high cost, daylight-controlled lighting systems support a fixed illuminance level at low daylighting values and supply lighting comfort for users. Since the aim of the study is energy efficiency, shading studies have not been conducted in cases where the daylighting value is high. It has been found that the payback period can be reduced by 5 years with the proposed system compared to conventional daylighting control systems. Also, the proposed system supplies advantages such as $59 \%$ energy savings, instant data monitoring of system current, voltage, power, and illuminance, as well as remote intervention.

\section{ACKNOWLEDGEMENT}

This work was supported by the Scientific Research Projects Coordination Unit of Kocaeli University under contract number 2018/072.

\section{REFERENCES}

1. Paz J.F.D., Bajo J., Rodríguez S., Villarrubia G., Corchado J.M., Intelligent system for lighting control in smart cities, Information Sciences, 2016. V372, pp. 241-255.

2. Radulovic D., Skok S., Kirincic V., Energy efficiency public lighting management in the cities, Energy, 2011. V36, \#4, pp. 1908-1915.

3. Zou H., Zhou Y., Jiang H, Chien Z.C., Xie L., Spanos C.J., WinLight: A WiFi-based occupancy-driven light- 
ing control system for smart building, Energy and Buildings, 2018. V158, pp. 924-938.

4. Rosenberg E., Calculation method for electricity end-use for residential lighting, Energy, 2014. V66, pp. 295-304.

5. Yahiaoui A., Experimental study on modelling and control of lighting components in a test-cell building, Solar Energy, 2018. V166, pp. 390-408.

6. Darula S., Review of the current state and future development in standardizing natural lighting in interiors, Light \& Engineering, 2018. V26, \#4, pp. 5-26.

7. Santamouris M., Dascalaki E., Passive retrofitting of office buildings to improve their energy performance and indoor environment: the office project, Building and Environment, 2002. V37, pp. 575-578.

8. Chi D. A., Moreno D., Navarro J., Correlating daylight availability metric with lighting, heating and cooling energy consumptions, Building and Environment, 2018. V132, pp. 170-180.

9. Doulos L., Tsangrassoulis A., Topalis F.V., Multicriteria decision analysis to select the optimum position and proper field of view of a photosensor, Energy Conversion and Management, 2014. V86, pp. 1069-1077.

10. Barbón A., Pardellas A., Fernández-Rubiera J.A., Barbón N., New daylight fluctuation control in an optical fiber-based daylighting system, Building and Environment, 2019. V153, pp. 35-45.

11. Ovcharov A.T., Selyanin Y.N., Antsupov Y.V., A hybrid illumination complex for combined illumination systems: concepts, state of the problem, practical experience, Light \& Engineering, 2018. V26, \#2, pp. 20-28.

12. Dubois M.C., Blomsterberg A., Energy saving potential and strategies for electric lighting in future North European, low energy office buildings: A literature review, Energy and Buildings, 2011. V43, pp. 2572-2582.

13. Shen E., Hu J., Patel M., Energy and visual comfort analysis of lighting and daylight control strategies, Building and Environment, 2014. V78, pp. 155-170.

14. Chew I., Kalavally V., Oo N.W., Parkkinen J., Design of an energy-saving controller for an intelligent LED lighting system, Energy and Buildings, 2016. V120, pp. 1-9.

15. Yu X., Su Y., Daylight availability assessment and its potential energy saving estimation -A literature review, Renewable and Sustainable Energy Reviews, 2015. V52, pp. 494-503.

16. Sahana S., Roy B., Development and performance analysis of a cost-effective integrated light controller, Light \& Engineering, 2019. V27, \#6, pp. 73-81.

17. Alexei K. Soloviev, Nina A. Muraviova, Sergei V. Stetsky, Comfort light environment under natural and combined lighting method of their characteristics definition with subjective expert appraisal using, Light \& Engineering, 2018. V26, \#3, pp. 124-131.

18. Dun W., Optimization of intelligent illumination in university classroom based on FMRAS control algorithm, Light \& Engineering, 2018. V26, \#2, pp. 52-59.

19. Cheng R., Classroom lighting energy-saving control system based on machine vision technology, Light \& Engineering, 2018. V26, \#4, pp. 143-149.

20. Jain S., Garg V., A review of open loop control strategies for shades, blinds and integrated lighting by use of real-time daylight prediction methods, Building and Environment, 2018. V135, pp. 352-364.

21. Pandharipande A., Caicedo D., Smart indoor lighting systems with luminaire-based sensing: A review of lighting control approaches, Energy and Buildings, 2015. V104, pp. 369-377.

22. Soori P.K., Vishwas M., Lighting control strategy for energy efficient office lighting system design, Energy and Buildings, 2013. V66, pp. 329-337.

23. Nikolaevich A. V., Light desynchronosis and healt, Light \& Engineering, 2019. V27, \#3, pp. 14-25.

24. Ihm P., Nemri A., Krarti M., Estimation of lighting energy savings from daylighting, Building and Environment, 2009. V44, \#3, pp. 509-514.

25. Gentile N., Dubois M, Laike T., Daylight harvesting control systems design recommendations based on a literature review, Environment and Electrical Engineering (EEEIC), 2015 IEEE15th International Conference on Rome, Italy, 10-13 June, ISBN: 978-1-4799-7994-3, 2015. pp. 632-637.

26. Pandharipande A., Willems F.M.J., Daylight-adaptive lighting control using light sensor calibration prior-information, Energy and Buildings, 2014. V73, pp 105-114.

27. Tang S., Kalavally V., Ng K.Y., Parkkinen J., Development of a prototype smart home intelligent lighting control architecture using sensors onboard a mobile computing system, Energy and Buildings, 2017. V138, pp. 368-376.

28. Meugheuvel N.V.D.M., Pandharipande A., Caicedo D., Hof P.P.J.V.D., Distributed lighting control with daylight and occupancy adaptation, Energy and Buildings, 2014. V75, pp. 321-329.

29. Türkiye Cumhuriyeti Enerji Piyasası Düzenleme Kurumu [Republic of Turkey Energy Market Regulatory Authority]. URL: https://www.epdk.org.tr/Detay/Icerik/3-0-1/tarifeler (referance date: 29.10.2019) 


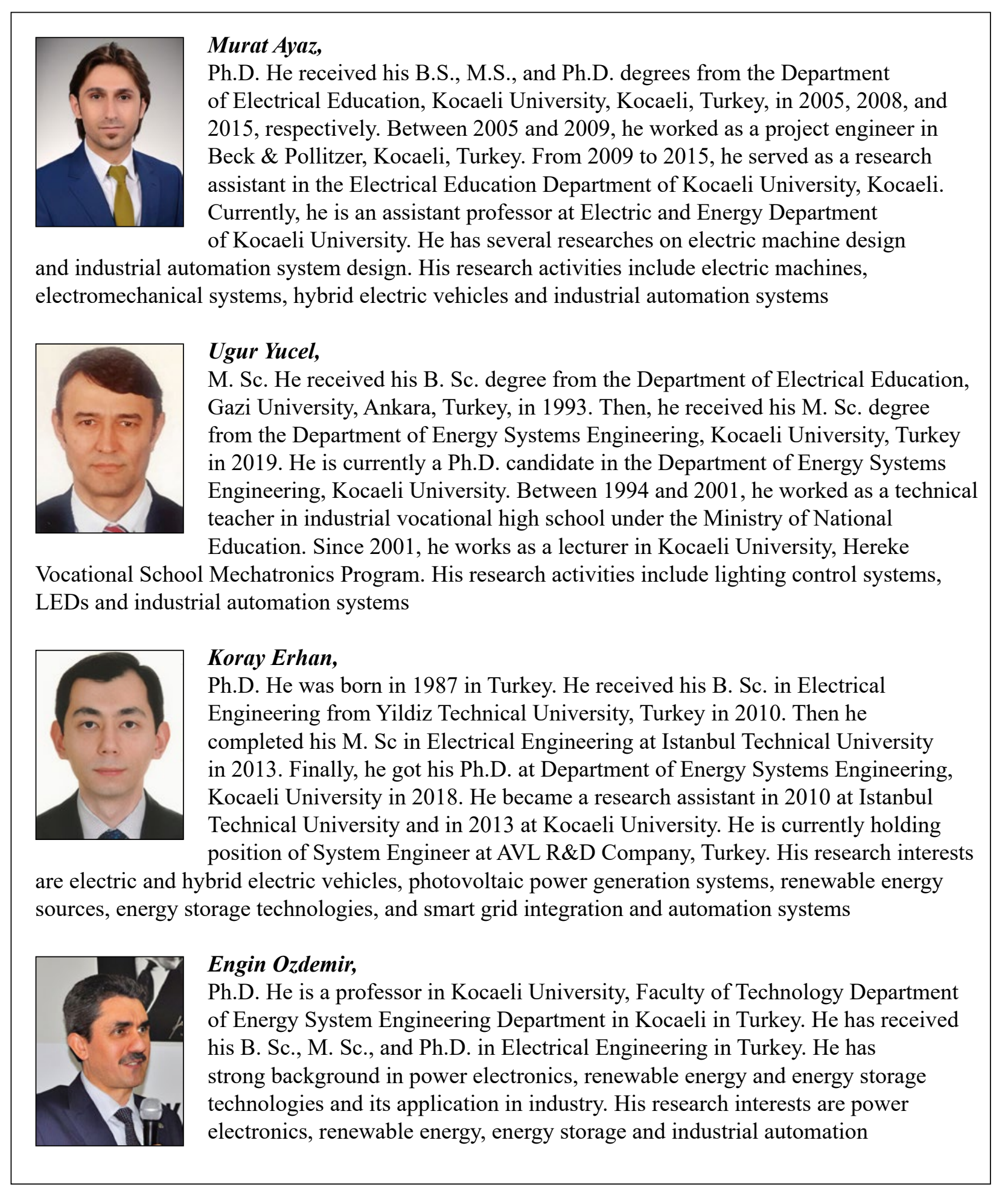

